\title{
Advances in the Breeding of Bell Pepper - A Review
}

\author{
Radhika Negi ${ }^{1}$, Seema Thakur ${ }^{2 *}$ and Payal Sharma ${ }^{1}$ \\ ${ }^{1}$ Department of Vegetable Science, Dr YS Parmar, UHF, Nauni, Solan, H.P., India \\ ${ }^{2}$ Department of Vegetable Science, KVK, Solan, H.P., India
}

*Corresponding author

\begin{tabular}{|c|}
\hline$K$ \\
\hline $\begin{array}{l}\text { Bell pepper, } \\
\text { biotechnology, } \\
\text { anther culture, } \\
\text { abiotic factors }\end{array}$ \\
\hline Article Info \\
\hline $\begin{array}{l}\text { Accepted: } \\
20 \text { March } 2018 \\
\text { Available Online: } \\
10 \text { April } 2018\end{array}$ \\
\hline
\end{tabular}

\section{Keywords}

Bell pepper, biotechnology, anther culture, abiotic factors

Article Info

Accepted:

Available Online:

10 April 2018

\section{A B S T R A C T}

Bell pepper is known as "Shimla Mirch" and is extensively cultivated in hills of Himachal Pradesh, Uttar Pradesh, Jammu and Kashmir, Andhra Pradesh and Nilgiri during summer months and as an autumn crop in Karnataka, Maharashtra, Tamil Nadu, Bihar, West Bengal and Madhya Pradesh. In Himachal Pradesh, it is grown as an off season crop during the summer and rainy seasons and is economically important to small and marginal farmers. Germplasm collection and conservation is the major step in improvement of sweet pepper and this material can be used in hybridization programme. Quality specifications such as size, shape, colour and non-pungency make the task of developing new hybrids/cultivars very challenging. Besides conventional breeding methods molecular genetics, tissue culture, and genetic engineering are becoming increasingly important. Use of biotechnology will likely to aid in the future development of improved bell pepper varieties. Bell pepper is very much sensitive to biotic and abiotic stresses and thus there is an urgent need to develop multiple disease resistant varieties. The cultivation of bell pepper is only possible in few states as prone to abiotic stresses so there is need to develop varieties for its cultivation in non-traditional areas.

\section{Introduction}

Bell Pepper (Capsicum annuum L. var. grossum) commonly known as Shimla Mirch or Capsicum or Sweet Pepper is a Solanaceous vegetable and is popular for its delicious taste, pleasant flavour and nutritional qualities. Many important quality traits are present in bell pepper, including taste, aroma, flavour, colour, vitamins, and carotenoid pigments. It is one of the major vegetable crop occupying large areas under open field as well as in protected structures.

The pepper fruits can be consumed fresh, cooked as vegetable or widely used in stuffings and are of great importance for their high nutritional value and the fact that the vitamins are wholly used by the human body (Sbirciog, 2012). 
Germplasm collection and conservation is the major step in improvement of sweet pepper and this material can be used in hybridization programme. Quality specifications such as size, shape, colour and non-pungency make the task of developing new hybrids/cultivars very challenging (Kumari, 2015). Breeders must set objectives for breeding of pepper in order to obtain varieties or hybrids that meet the requirements of growers and consumers. The main general objectives of breeding pepper are yielding capacity, earliness and vigour, fruit quality, resistance to pathogens, and stress tolerance. Breeding teams are very concerned about the introduction of disease resistance and have introduced resistance to TMV (from C. frutescens), PMMV (from C. chinense), Potato Virus Y, CMV (from C. baccatum).

Research on resistance to Xanthomonas campestris $p v$. Vesicatoria showed that there are several sources of resistance by hypersensitivity conditioned by genes Bs (Bs1-Bs6). Resistance to Phytophthora capsici proved polygenic type. Breeders use different schemes for improvement: mass selection, pedigree breeding, SSD, recurrent selection, backcross and induction of mutations.

Progress on genetic engineering, peppers is modest compared to other species, though some results are noticeable. Breeders can use these genotypes to create valuable cultivar, which in addition to the characters or qualities mentioned will have high production capacity, high quality fruit and organoleptic characteristics demanded by consumer (Sbirciog et al., 2016).

Its research and development is focused on varieties that may also be suitable for nontraditional areas where bell pepper is yet to be introduced. The development of hybrids and economic hybrid seed production technology is rapidly being adopted by seed companies.

\section{Origin and taxonomy}

Bell pepper originated in Southern and Central America. Bell pepper is a native of Mexico with secondary centre of origin in Gautemala (Bukasov, 1930). Columbus introduced Capsicum in to Spain on his return trip in 1493. In India, it was introduced by the Britishers in the 19th century in Shimla hills. In India, the term Capsicum is often used for the fruits of bell peppers. In actual sense, Capsicum is a genus with five domesticated species including:

Capsicum annuum L. (origin Mexico), having a toothed calyx.

Capsicum frutescens L. (origin Amazonia), having a greenish flower and non-toothed calyx.

Capsicum chinense (origin Amazonia), having a constricted toothed calyx.

Capsicum baccatum L. (origin Amazonia), having a corolla with yellow/brown spots.

Capsicum pubescens (origin Peru and Bolivia), having black colored seeds and purple flowers.

\section{Area and production}

In India, it is cultivated over an area of about 46,000 ha with annual production of 288,000 MT (National Horticulture Board, 2016). This crop is extensively cultivated in hills of Himachal Pradesh, Uttar Pradesh, Jammu and Kashmir, Andhra Pradesh and Nilgiris during summer months and as an autumn crop in Karnataka, Maharashtra, Tamil Nadu, Bihar, West Bengal and Madhya Pradesh. In Himachal Pradesh, it is grown as an off season crop during the summer and rainy seasons and is economically important to small and marginal farmers (Sood et al., 2009). 


\section{Importance and uses}

Bell pepper is grown as autumn- winter crop in the plains and summer crop in the hill regions of India. It is consumed both in green mature and ripe form, raw in salads, cooked, mixed and stuffed vegetable. It is widely used in the preparations of pickles, sauces, soups and stews. Ascorbic acid present in it aid in prevention of certain types of cancer, cardiovascular diseases, stroke, and cataracts. It helps to normalize blood pressure levels. It controls blood pressure and prevents cancer. The rich vitamin $\mathrm{C}$ content present in it mainly prevents Blood Clotting.

\section{Breeding objectives in bell pepper}

High yield

Earliness

Desirable fruit shape and size: oblate or round

Superior fruit qualities like high vitamin $\mathrm{C}$ and pigment content, pleasing flavour, etc.

Resistance to diseases like fruit rot, cercospora leaf spot, powdery mildew, common TMV, etc.

Resistance/tolerance to insects like thrips, mites, aphids, fruit borer.

Resistance/tolerance to abiotic stresses like heat, water stress, salinity.

\section{Breeding methods}

Bell pepper is an often cross pollinated crop. Various breeding methods used are:

\section{Conventional breeding methods}

Introduction

Selection

Pureline Selection
Pedigree Method

Backcross Method

Heterosis

Mutation Breeding

\section{Non-conventional breeding methods}

Tissue culture

Genetic engineering

\section{Introduction}

Introducing a plant into new regions from its growing locality.

Proper management is necessary.

While introducing a variety into new region care should be taken that introducing material should not carry any insect-pest.

In bell pepper, International Board of Plant Genetic Resources (IBPGR), Rome, and Asian Vegetable Research and Development Centre (AVRDC), Taiwan, are important international sources for enriching the germplasm base.

Varieties introduced from different countries are commonly used as a source of new variability, especially open pollinated cultivars like California Wonder, Yolo Wonder, Bull Nose, Chinese Giant, World Beater, etc.

Some promising direct introductions in bell pepper

California Wonder: Introduction from IARI, New Delhi from USA.

Yolo Wonder: Introduction from IARI, New Delhi from USA

Chinese Giant: Introduced by IAHS, Bangalore. 
World Beater: Introduced by IAHS, Some of such cultivars are Bangalore.

Ruby King

Spartan Garnet: (California Wonder $\times$ Dwarf Pimiento Selection from variety Santanka)

King of North

Spartan Emerald: (Morgold $\times$ California Wonder)

\section{Pureline selection}

Pureline is a progeny of single homozygous plant.

Initial seed stock is space planted and superior plants are selected and harvested separately in the year.

Next year, individual plant progenies are grown and progeny showing superior performance is bulk harvested and evaluated further with check cultivars in replicated trial.

\section{Varieties developed by selection}

Arka Mohini: Selection from Titan of USA by IIHR, Bangalore.

Arka Gaurav: Selection from Golden Calwonder of USA by IIHR, Bangalore. Indeterminate variety tolerant to bacterial wilt. Arka Basant: Selection from Hungarian variety 'Soroksari' by IIHR, Bangalore. Excellent keeping and cooking qualities.

Nishat 1: A selection from Capsicum Sel-2 (SKUAS\&T, Srinagar)

\section{Pedigree method}

This method involves:

Selection of superior plants in the segregating generations.

Hybridization is done between superior cultivars along with maintenance of pedigree record.

Sonnette: An F2 line (Morgold $\times$ California Wonder) $\times$ Keystone Resistant Giant.

\section{Backcross method}

Used to transfer disease resistant genes from primitive cultivars/wild forms to leading cultivars.

Back crossing has been an essential method for introgressing genes from hot pepper into sweet pepper and from interspecific crosses. For fruit quality, disease resistance, or any other specific attribute a pure line can be improved by backcrossing to incorporate novel genes.

In bell pepper generally 4-5 backcrosses are required to produce near-isogenic lines for the novel gene in the pure line.

Backcrossing is used whenever disease resistance, improvement of male sterile line or any other simply inherited morphological trait is to be transferred because its application is convenient in bell pepper.

Incorporation of resistance (powdery mildew) from C. baccatum var. pendulum

\section{Mutation breeding method}

\section{Seed treatment}

Seeds possessing $96-100 \%$ germinability and moisture content (about 13\%) are recommended to obtain good reproducibility of results. 
Three doses should be applied to assure survival of $40-60 \%\left(\mathrm{LD}_{40-60}\right)$ after ionizing radiation treatments and $70-80 \%\left(\mathrm{LD}_{20-30}\right)$ following treatments with chemical mutagens.

Dose range for gamma and X-rays is $60-400$ Gy.

\section{Gametophyte treatment}

Mature pollen grains are collected from already dehiscent anthers for mutagenic treatment.

Dose range is $5-15$ Gy.

Immediately after irradiation, the pollen must be used for pollination of emasculated nonirradiated flowers.

The pollination is carried out in insect-proof glasshouses or the pollinated flowers are isolated with paper bags to avoid outcrossing.

\section{Mutant varieties}

Albena, Lyulin, Horgoskaslatka-X-3.

\section{Heterosis breeding}

The goal of increasing productivity in the quickest possible time can be achieved by utilizing heterosis breeding.

An $F_{1}$ hybrid variety is the result of a cross between two homozygous (but genetically distinct) pure lines.

The prerequisite is that all the F1 plants should resemble each other phenotypically.

First hybrid variety was Bharat.

The great success of hybrid cultivars is attributed to:
Sufficiently large flowers, easy emasculation and pollen in abundance.

Heterosis for yield.

Large number of crossed seeds/fruit.

Easy deployment of dominant genes conferring resistance to diseases.

Highly remunerative price of hybrid seed.

\section{Hybrid development}

\section{Public sector hybrid}

Pusa Deepti (Kt-1):- hybrid between Yolo Wonder and Runion Yellow, released by IARI Regional Station, Katrain (HP). High yielding, tolerant to bacterial leaf spot and anthracnose.

Solan Hybrid-2:- Released by YSPUHF, Solan. Resistant to fruit rot and virus.

Solan Hybrid-1: Released by YSPUHF, Solan.

Solan Bharpur: Released by YSPUHF, Solan.

KTCPH- 3: Yolo Wonder x HL-201, released by IARI Regional Station, Katrain (HP).

KTCPH- 5: Yolo Wonder x EC- 143570 , released by IARI Regional Station, Katrain (HP).

Punjab- 27

\section{Molecular markers}

Molecular markers have proved to be invaluable for understanding the genetic make-up of agricultural crops. A variety of molecular markers have been used in pepper are Isozymes. These are protein molecules that are separated electrophoretically based on their charge 
Gels are stained for specific enzyme activity and, by doing so, allelic and non-allelic proteins can be identified

Isozymes have been used to examine systematic relationships of Capsicum cardenasii, $C$. eximium, $C$. pubescens, $C$. tovarii

Analysis of the esterase isozymes in 15 accessions of $C$. annuum from United States, Mexico, Central America and South America showed three different isozyme patterns

Accessions from Peru, Central America and other accessions from the United States all shared a second pattern of isozyme banding

The third pattern of isozymes including of the hybrids produced when accessions from the first two pattern groups were crossed with one another

The isozyme data combined with the cytological data provide evidence for the theory that Mexico is the centre of domestication of C.annuum

\section{Restriction Fragment Length polymorphisms (RFLPs)}

Restriction Fragment Length polymorphisms utilize restriction enzymes that cut genomic DNA at specific sites

The cut DNA fragments are separated by electrophoresis then transferred and immobilized on to nitrocellulose paper

The fragment are then probed, usually with cloned, radioactively labelled probe DNA fragments which are typically 500-3000 base pairs long

RFLPs can distinguish homozygous from heterozygous individuals, but they are expensive, require technical expertise and have the further disadvantage of utilizing radioactive material. In Capsicum research, RFLPs have been used for genetic mapping.

\section{Anther culture}

Induction and regeneration of haploid embryos from anthers or microspore culture facilitate recovery of recessive mutations and unique genetic recombinations. The doubling of the haploid genome results in fully homozygotic lines in shortened period which is important for creation of genetic diversity and a base of new varieties with higher quality. Production of doubled haploids (DHs) is a convenient tool to obtain pure lines for breeding purposes. Anther culture is still considered the method of choice for pepper double haploid production due to its simplicity (Germana, 2011). It is widely accepted that anther culture promotes the formation of microspore-derived embryos, and that the genotype has a remarkable influence in the percentage of microspores deviated towards embryogenesis and effectively transformed into embryos (Irikova et al., 2011).

Parra-Vega Verónica et al., (2013) revealed that culture conditions have a significant influence on the presence of calli derived from anther walls, which could be minimized by reducing heat shock exposure and/or using a shed-microspore approach in sweet pepper.

They concluded that In conclusion, we showed that culture conditions have a notable influence, even higher than the genotype, on the formation of callus from sweet pepper anther walls.

This influence could be minimized in general by reducing heat shock exposure to a minimum when cultured in solid medium, or by using the shed-microspore approach in particularly sensitive genotypes. 
Utilization of GMS: Bell Boy and No. 12 were two F $_{1}$ hybrids developed by using GMS in Bell Pepper

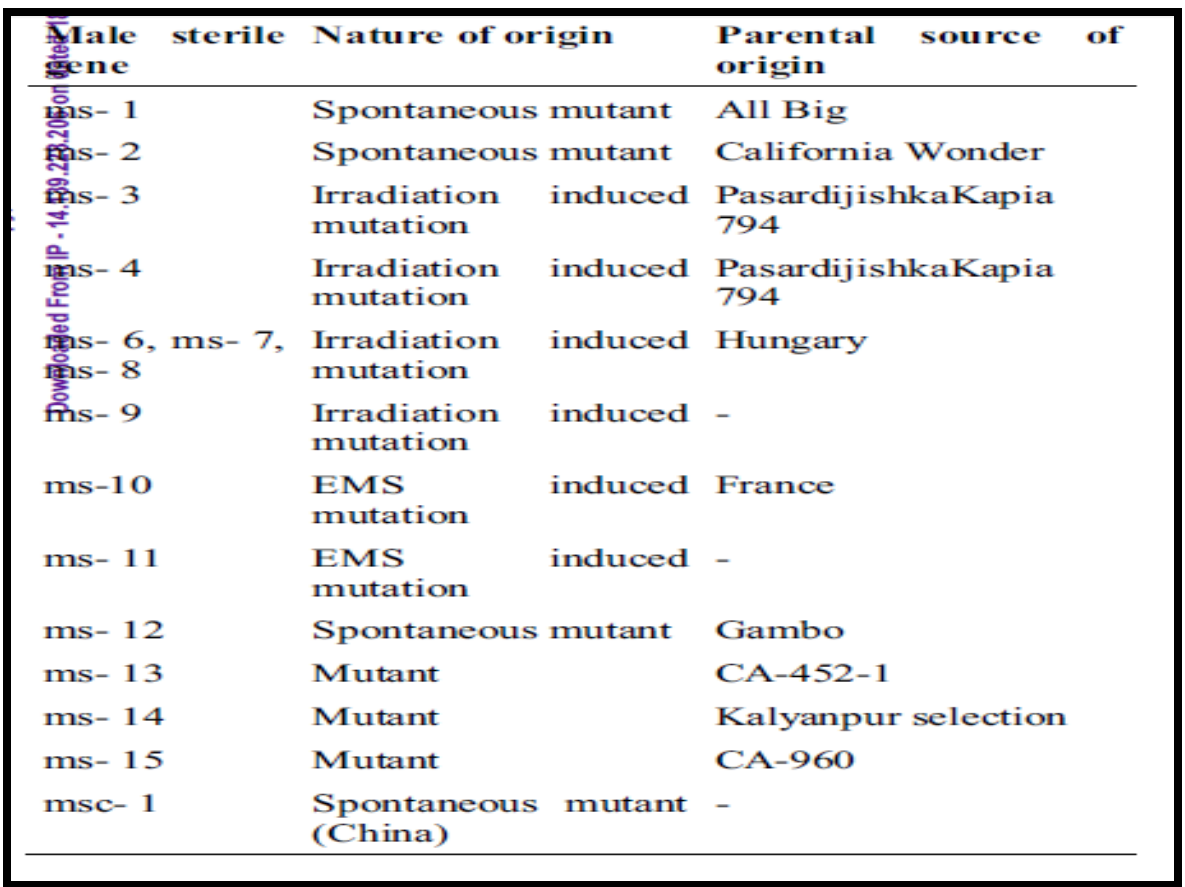

\section{Root-Knot Nematode Resistant Bell Peppers}

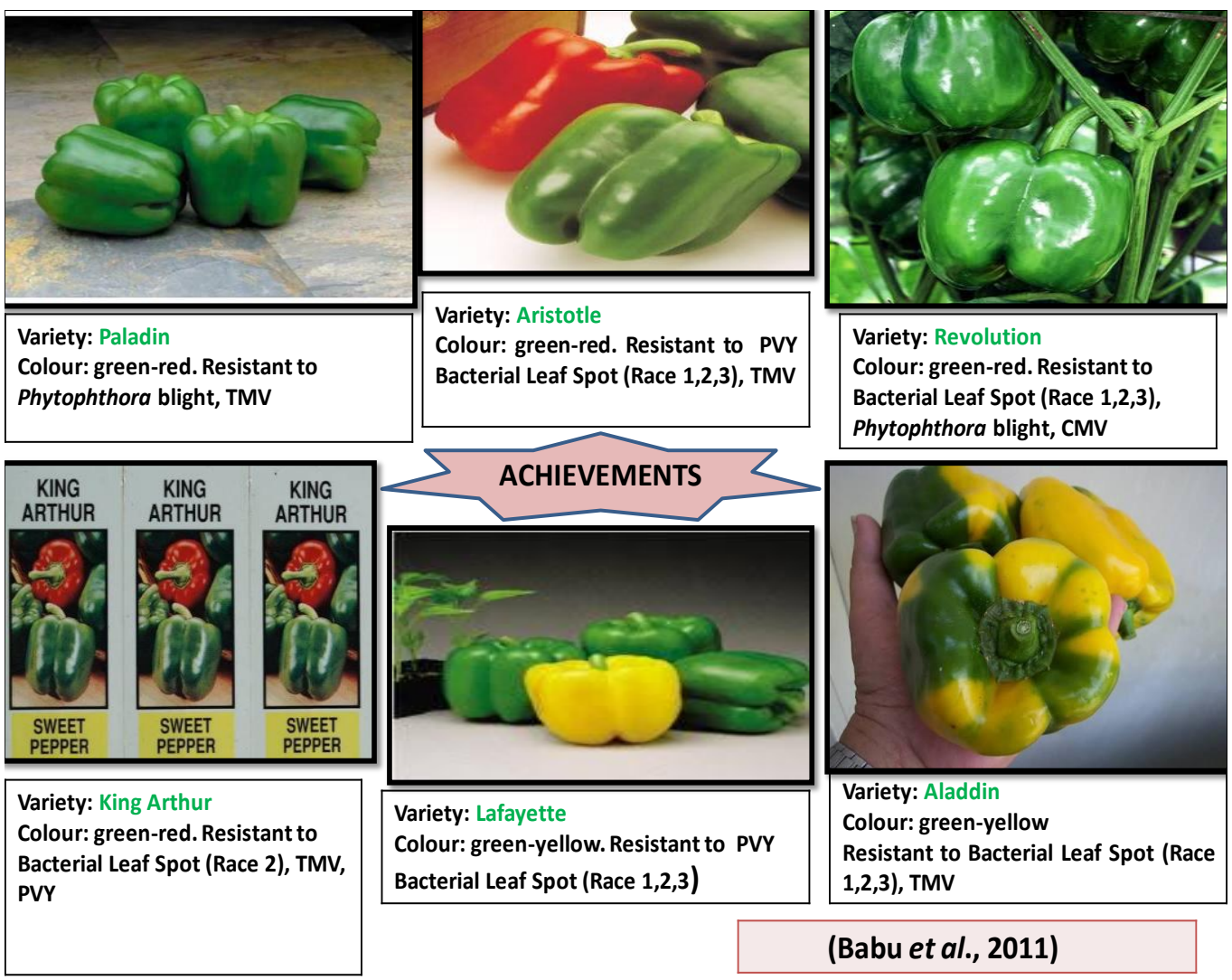




\section{Double haploids}

To create new varieties resistant to biotic and abiotic stress factors that possess high productivity and improved fruit quality, breeders require modern breeding methods and techniques.

Double haploid lines are an invaluable breeding element due to their guaranteed, completely homozygous nature. One of the fastest methods for obtaining $\mathrm{DH}$ lines is anther culture.

In conclusion bell pepper varieties have evolved from local land races to advanced hybrid development.

Use of biotechnology will likely aid in the future development of improved bell pepper varieties.

Besides conventional breeding methods molecular genetics, tissue culture, and genetic engineering are becoming increasingly important.

Exploitation of heterosis in vegetable crops has attracted attention of vegetable breeders to the vegetable requirements of the increasing population.

There are alternative systems to produce hybrid seed, but the production of bell pepper hybrid seed commercially still relies on making crosses between two parents by conventional hand pollination, a very labour intensive and expensive process.

The future outlook for bell pepper is good.

\section{Future prospects}

As bell pepper is very much sensitive to biotic and abiotic stresses and thus there is an urgent need to develop multiple disease resistant varieties. Cultivated only in few states as prone to abiotic stresses so there is need to develop varieties for its cultivation in nontraditional areas.

\section{Advances in hybrid seed production}

\section{Hybrid seed production}

The $F_{1}$ hybrids of sweet pepper have been commercially exploited in India

Steps involved in production of hybrid seed production are:

\section{Hand emasculation and pollination}

\section{Emasculation}

Emasculation is done in the afternoon hours, a day prior to anthesis, because in some genotypes dehiscence of anthers takes place before anthesis. Emasculation is done with the forceps by gently parting the corolla and picking of anthers. Emasculated flowers are occasionally visited by honey bees and natural cross production ranges from $35-38$ percent. So, the emasculated flowers are either bagged or protected by thin cotton wad.

\section{Collection of pollen}

Fresh powdery pollen grains may be collected on the day of anthesis either by vibrator or by tapping the plucked flowers over a glass container. The pollens could be stored for a period of 1-2 months in a desiccators at $0^{\circ} \mathrm{C}$ temperature.

\section{Pollination}

Pollination is done in the afternoon hours, upto 10:00 am, normally on the day of anthesis. Though stigma remains receptive up to 2 days after anthesis, yet pollination should be done on the day of anthesis to achieve 
maximum fruit set. Stigma also becomes receptive a day prior to anthesis. Fruit sets in flower bud, pollinated a day prior to anthesis, has been found to be satisfactory.

In this bud pollination method, emasculation and simultaneous pollination both are done in the morning hours. Flowering and fruit set requires bright sunlight, hence hybridization should be avoided in cloudy days. Spraying of 10 ppm NAA at flowering and seven days after, checks flower drop and increases fruit set by hybridization.

\section{Use of male sterility}

Both genic and cytoplasmic male sterility have been reported in sweet pepper. Functional male sterility can successfully be utilized in hybrid seed production.

Male sterility is one of the most important traits used in hybrid pepper breeding. Application of male sterility reduces hybrid production costs by excluding the need for manual emasculation of maternal line and elimination of impurities of the seed material originated from self-pollination.

\section{Reported male sterility genes in Capsicum}

\section{Disease resistant varieties of bell peppers}

Fruit rot: Hungarian Yellow Wax, Spartan, Chinese Giant, Yolo Y

Cercospora Leaf Spot: California Wonder, Hungarian Wax

Bacterial Leaf Spot: PI -163192, 260435

Root Rot: Santaka, 'Charleston Belle', 'Charleston Hot', 'Carolina Wonder', 'Carolina Cayenne', and 'Mississippi Nemaheart'
TMV: Sonnette, Keystone Resistant Giant, Yolo Y.

\section{Root-knot nematode resistant bell peppers}

Thies et al., (2008) evaluated two root-knot nematode-resistant bell pepper cultivars, 'Charleston Belle' and 'Carolina Wonder' (Capsicum annuum L. var. annuum], and their susceptible parents, 'Keystone Resistant Giant' and 'Yolo Wonder B', were compared for managing the southern root-knot nematode [Meloidogyne incognita (Chitwood) Kofoid and White] in fall and spring tests at Citra, FL. In the fall test, 'Charleston Belle' and 'Carolina Wonder' exhibited minimal root galling and nematode reproduction, and 'Keystone Resistant Giant' and 'Yolo Wonder B' exhibited severe root galling and high nematode reproduction. Fruit yield of 'Charleston Belle' was 97\% greater than yields of the two susceptible cultivars ( $\mathrm{P}$ 0.006).

In the spring test, one-half of the plots were treated with methyl bromide/chloropicrin before planting the same four bell pepper cultivars. 'Keystone Resistant Giant' and 'Yolo Wonder B' grown in untreated control plots exhibited severe root galling and high nematode reproduction, but the other six cultivar $\mathrm{x}$ methyl bromide combinations exhibited minimal root galling and nematode reproduction. Although soil temperatures (10$\mathrm{cm}$ depth) were greater than $30{ }^{\circ} \mathrm{C}$ on 78 days and 57 days during the Fall 2002 and Spring 2003 trials, respectively, resistance did not break in 'Charleston Belle' and 'Carolina Wonder' in either test. These results demonstrate that root-knot nematode-resistant cultivars such as Charleston Belle and Carolina Wonder are viable alternatives to methyl bromide for managing southern rootknot nematode in bell pepper in sub-tropical environments. 


\section{References}

Bukasov SM. 1930. The cultivated plants of Mexico, Guatemala and Columbia. Bulletin of Applied Botanical Genetics and Plant Breeding 47 (Supple 4):26173.

Germana MA. 2011. Anther culture for haploid and doubled haploid production. Plant Cell, Tissue Organ Cult 104:283-300.

Irikova T, Grozeva S, Rodeva V. 2011. Anther culture in pepper (Capsicum annuum L.) in vitro. Acta Physiol Plant 33:1559-70.

Kumari S and Sharma M. 2014. Screening bell pepper germplasm for resistance against Phytophthora leaf blight and fruit rot disease. International Journal of Farm Sciences 4:76-80.

NHB. 2016. National Horticulture Board Database 2015-16. www.nhb.gov.in

Parra-Vega Verónica, Renau-Morata Begoña, Sifres Alicia and Segur'-
Simarro Jose' M. 2013. Stress treatments and in vitro culture conditions influence microspore embryogenesis and growth of callus from anther walls of sweet pepper (Capsicum annuum L.). Plant Cell Tissue Organ Cult 112: 353-60.

Sbirciog G, Buzatu A, Mandru I and Scurtu I. 2016. Achievements in Pepper Breeding at Research Development Institute for Vegetable and Flower Growing - Vidra. Current Trends in Natural Sciences 5:33-37.

Sbirciog G. 2012. New Pepper (Capsicum annuит L.) Genotypes Created at ICDLF Vidra. Bulletin of University of Agricultural Sciences and Veterinary Medicine Cluj -Napoca 69:425.

Sood S, Sood R, Sagar V and Sharma KC. 2009. Genetic variation and association analysis for fruit yield, agronomic and quality characters in bell pepper. Indian Journal of Vegetable Science 15:27284.

\section{How to cite this article:}

Radhika Negi, Seema Thakur and Payal Sharma. 2018. Advances in the Breeding of Bell Pepper - A Review. Int.J.Curr.Microbiol.App.Sci. 7(04): 2272-2281. doi: https://doi.org/10.20546/ijcmas.2018.704.260 